\title{
Reproductive performance in relation to uterine and embryonic traits during early gestation in Meishan, Large White and crossbred sows
}

\author{
J. M. Galvin ${ }^{1}$, I. Wilmut ${ }^{2}$, B. N. Day ${ }^{1}$, M. Ritchie ${ }^{2}$, M. Thomson ${ }^{2}$ \\ and C. S. Haley ${ }^{2 *}$ \\ ${ }^{1}$ Department of Animal Science, University of Missouri, Columbia, MI 65211, USA; and \\ ${ }^{2} A F R C$ Roslin Institute (Edinburgh), Roslin, Midlothian EH25 9PS, UK
}

Previous studies have shown that females of the Chinese Meishan breed and of their $F_{1}$ cross with European Large White pigs are very prolific, producing about four more piglets per litter than control Large White females. The main cause of this prolificacy is enhanced prenatal survival for a given ovulation rate in Meishan and $F_{1}$ females and this is controlled by genes of the mother, not those of the conceptus. The objectives of this study were to determine whether genotypic differences in embryo survival were apparent in the period immediately after attachment and to compare embryonic and uterine development at this time. Sows in their third parity (20 Large White, 14 Meishan, 25 Large White $\times$ Meishan $F_{1}$ and 25 Meishan $\times$ Large White $F_{1}$ ) were killed 20-22 days after mating and their reproductive tracts recovered for further study. There were significant differences between the purebred sows, and crossbred sows were approximately intermediate for the number of corpora lutea $(20.7 \pm 0.9,27.8 \pm 1.1,22.4 \pm 0.8$ and $23.3 \pm 0.8$ for the four genotypes, respectively), the number of embryos (15.2 $\pm 0.9,23.4 \pm 1.1,17.2 \pm 0.8$ and $18.8 \pm 0.8$, respectively) and the proportionate embryo survival $(0.74 \pm 0.04,0.84 \pm 0.04,0.78 \pm 0.03$ and $0.82 \pm 0.03$, respectively). There was a negative association within genotype between embryo survival and the number of corpora lutea. Adjusting for the genotypic difference in the number of corpora lutea increased the genotypic differences in embryo survival. Meishan uteri were similar in weight to, although significantly shorter than, those from Large White females. Significant heterosis meant that uteri from $F_{1}$ females were both heavier and longer than those from either pure breed. Embryo attachment sites were significantly closer together in Meishan uteri than they were in uteri of the other genotypes. The head length and weight of embryos and the weight of the placentae did not differ significantly between the pure breeds, but were increased in $F_{1}$ sows, significantly so for head length and the weight of the placentae. Within sow variation in distances between embryo attachment sites was less in Meishan and $F_{1}$ females than in Large White females. Within sow variation in the head length and weight of embryos and in the weight of the placentae was always less in Meishan and $\mathrm{F}_{1}$ females than in Large White females, but this difference was only significant for the weight of the embryos in $\mathrm{F}_{1}$ females. Meishan females have higher ovulation rates and a higher level of embryo survival after attachment than do Large White females. At this stage the number of embryos in $F_{1}$ females is intermediate between the two pure breeds. $F_{1}$ females must have very high levels of fetal survival, thus achieving similar litter sizes to purebred Meishan females by a different route. Heterosis in $\mathrm{F}_{1}$ females for increased uterine dimensions and embryonic growth and decreased variability between embryos may be factors associated with high fetal survival.

\section{Introduction}

The Chinese Meishan breed of pig is one of the most prolific breeds in the world, producing three to four more piglets per litter than females of the European Large White breed (Cheng, 1983; Bidanel et al., 1989; Haley and Lee, 1990). Although the

*Correspondence

Received 6 July 1992.
Meishan is not commercially viable in the West owing to poor growth and carcass characteristics (Bidanel et al., 1990b; Haley et al., 1992; Serra et al., 1992), the physiological basis and genetic control of prolificacy in the Meishan pig is of considerable interest. In particular, an understanding of the causes of prolificacy may lead to improved crossbreeding, selection criteria or other means of improving litter size in Western pig breeds. 
In both France (Bidanel et al., 1989) and the UK (Haley and Lee, 1990), crossbreeding studies between the Meishan and the Large White have demonstrated that prolificacy is mainly controlled by genes in the dam (i.e. the mother) and not those in the litter (i.e. embryo/fetus). Both of these studies also found a very high level of maternal heterosis, such that $F_{1}$ crossbred females produce litters of a similar size or larger than those of purebred Meishan females.

There are some discrepancies between studies of the components of litter size on the UK and French Meishan samples. Studies on the French sample have found that Meishan females have a similar or lower ovulation rate than Large White females (Bolet et al., 1986; Bazer et al., 1988; Bidanel et al., 1990a), whereas studies on the UK Meishan sample have found significantly higher ovulation rates in both gilts and sows than in Large White females (Ashworth et al., 1990, 1992; Haley and Lee, 1990; Wilmut et al., 1992). With no advantage to the Meishan in ovulation rate, the prolificacy of the French sample compared with the Large White breed is due to enhanced prenatal survival (Bolet et al., 1986; Bazer et al., 1988). Prenatal survival in the Meishan breed in the UK is only slightly greater than in the Large White breed (Haley and Lee, 1990). However, when the well documented negative association between ovulation rate and prenatal survival (reviewed by Wrathall, 1971) is accounted for, UK studies are consistent with those on the French Meishan sample. The Meishan sample in the UK appears to achieve its prolificacy by having a high level of prenatal survival for a given ovulation rate compared with the Large White breed (Haley and Lee, 1990). Use of crossbreeding allowed Haley and Lee (1990) to conclude that this high level of prenatal survival at a given ovulation rate was controlled by maternal genes; those of the embryo/fetus having little influence. The studies of litter size of Bidanel et al. (1989) suggest that this must also be the case for the French Meishan sample.

Studies to date have not been consistent in their conclusions about the factors that might influence prenatal survival or even when during gestation differences in prenatal survival first become apparent. Bazer et al. (1988) found a significant improvement in embryo survival at day 30 of gestation in Meishan compared with Large White gilts. Bazer et al. (1988) also concluded that Meishan embryos developed more rapidly and more uniformly than Large White embryos between days 8 and 14 of gestation and suggested that this might be a factor associated with their higher embryo survival. In a study of embryo survival in Meishan and Landrace $\times$ Large White crossbred gilts, Ashworth et al. (1992) found a nonsignificant difference in favour of the Meishan females in control gilts. Wilmut et al. $(1990,1992)$ compared embryonic development in Meishan and in Large White or European crossbred females and found no difference in the rate of development up to day 11 of gestation and only small differences in the within-sow variability between breeds. Anderson et al. (1991) compared embryonic development in Meishan and Large White crossbred sows at about day 12 of gestation and found that embryos from Meishan sows were smaller, with no difference in within-sow variability between breeds.

The results of studies of early gestation are thus equivocal and no studies have been performed on the period between attachment (about day 18 of pregnancy; Perry, 1981) and approximately day 30 of gestation. The purpose of the study described here was threefold: first, to compare embryo survival in Meishan and Large White gilts in the early post-attachment period to determine whether differences in embryo survival are apparent at this time; second, to compare embryonic development in the early post-attachment period to determine whether there are breed differences in size or variability; and third, by the inclusion of $F_{1}$ crossbred females in the trial, to investigate how heterosis acts to produce prolificacy in this genotype.

\section{Materials and Methods}

\section{Animals and treatment}

Sows were one of four genotypes, purebred Large White (LW), purebred Meishan (MS) or one of the two reciprocal $F_{1}$ genotypes, resulting from matings either between LW males and MS females ( $\mathrm{LW} \times \mathrm{MS}$ ) or between MS males and LW females (MS $\times$ LW). MS animals were derived from 21 gilts and 11 boars imported from China in 1987 and LW animals were derived from breeding companies and AI studs in 1980 (Cameron et al., 1988) and subsequently maintained without selection. All animals had previously produced two litters and sows of the four genotypes were of similar mean age (22-24 months at mating). Detection of oestrus was performed twice daily at around 09:00 and 16:00 h. Animals were mated when oestrus was first detected and again if still at oestrus $24 \mathrm{~h}$ later. All sows were mated either to one of seven Large White boars or to one of eight Meishan boars; repeat matings were to the same animal. Purebred sows, with the exception of one Meishan sow, were mated to boars of the same breed. Approximately equal numbers of each reciprocal crossbred sow genotype were mated to boars of the two pure breeds. A total of 99 sows were mated.

\section{Traits recorded}

Sows were slaughtered at a commercial abattoir 20,21 or 22 days after their first mating. The reproductive tracts of 86 pregnant sows were recovered and dissected on the same day. Ovaries were frozen for later dissection. The position of attachment of each embryo in the uterine tract was marked and the embryo/placental unit was dissected free from the uterus. The following information was recorded for each pregnant sow: sow genotype (LW, MS, MS $\times$ LW or LW $\times$ MS); boar genotype (LW or MS); number of serves (one or two); sow weight at slaughter $(\mathrm{kg})$; number of days between first mating and slaughter $(20,21$ or 22$)$; month of slaughter (July to September); uterine wet weight $(\mathrm{kg})$; uterine length $(\mathrm{cm})$; total length of the two horns; total number of corpora lutea found on dissection of the ovaries; number of embryo attachment sites found on dissection of the uterus; number of apparently viable embryos found on dissection of the uterus; embryo survival, calculated as number of viable embryos/number of corpora lutea.

The following information was recorded for each attachment site or embryo-placental unit: average of two distances from an individual embryo to the adjacent embryos or to the uterine tip or bifurcation (mm); length of head of embryo from tip of snout 
Table 1. The coefficients for each effect in the genetic model for each sow genotype

\begin{tabular}{|c|c|c|c|c|}
\hline \multirow[b]{2}{*}{ Genetic effect } & \multicolumn{4}{|c|}{ Genotype of sow } \\
\hline & $\begin{array}{l}\text { Large White } \\
\text { (LW) }\end{array}$ & $\begin{array}{l}\text { Meishan } \\
\text { (MS) }\end{array}$ & $\begin{array}{c}\mathrm{F}_{1} \\
(\mathrm{LW} \text { sire, MS dam) }\end{array}$ & $\frac{\mathrm{F}_{1}}{\text { (MS sire, } \mathrm{LW} \text { dam) }}$ \\
\hline \multicolumn{5}{|l|}{ dam } \\
\hline$m$ (mid-parental value) & 1 & 1 & 1 & 1 \\
\hline am (maternal additive effect) & -1 & 1 & 0 & 0 \\
\hline$d m$ (maternal heterosis effect) & 0 & 0 & 1 & 1 \\
\hline ag (grandmaternal additive effect) & -1 & 1 & 1 & -1 \\
\hline
\end{tabular}

to back, measured under a dissecting microscope at constant magnification in arbitrary graticule units; weight of dissected embryo ( $\mathrm{g}$ ); weight of dissected placental unit ( $\mathrm{g}$ ); number of attachment sites in the same uterine hom as embryo being measured; proportional position of embryo along uterine horn from tip to bifurcation measured on a zero to one scale; whether embryo one of a twin (classified as a twin when two embryos shared the same placenta).

\section{Statistical procedures and analyses}

General. All analyses were performed using the statistical package GENSTAT (GENSTAT 5 Committee, 1989) using either multiple regression (Draper and Smith, 1966) or restricted maximum likelihood (REML - Patterson and Thompson, 1971). In all cases, preliminary exploratory analyses were by stepwise multiple regression (Draper and Smith, 1966).

The main interest was in the estimation and interpretation of differences between genotypes of sows and two alternative analyses were performed. First, the sow genotype effect was included in the analytical model as four separate classes (for the two pure breeds and the two reciprocal $F_{1}$ genotypes). Second, the differences between sow genotypes were interpreted in terms of genetic parameters: the mid-parental value (mid-way between the pure breeds, signified by $m$ ), the additive effect of maternal genes (i.e. genes in the dam carrying the litter, signified by am), the effect of maternal heterosis $(\mathrm{dm})$ and the additive genetic effect of the grandmaternal breed (i.e. the breed to which the dam was born, signified by ag). This was achieved in the usual way (e.g. Dickerson, 1969) by replacing the effect of the genotypic class by the genetic parameters with the coefficients given in Table 1. In essence, am will only be significant if there is a difference between the pure breeds; $d m$ is a measure of the extent to which the $\mathrm{F}_{1}$ females deviate from the mean of the two pure breeds; and ag is a measure of the reciprocal difference between the $F_{1}$ females. The sow genotypic effects and the genetic parameters are alternatives that cannot be included in the same model as they both fully explain between-sow genotypic differences. As some $F_{1}$ sows were mated to purebred boars of each genotype, it would have been possible to extend the genetic model to include the effect of genotype of embryo/ fetus. The effect of boar genotype was included in the analyses but was never significant and so the inclusion of genotype of the embryo in the model was not considered worthwhile.
Where estimates of genotype means or genetic parameters were made in models including covariates which had mean values that differed between sow genotypes (such as sow weight or the number of corpora lutea), the estimates were adjusted to the approximate overall mean for the covariate. Where estimates of genotype means or genetic parameters were made in models including classified factors (such as the number of days between mating and slaughter or month of slaughter), the estimates were made for the first category of the factor.

Sow traits. For the analyses of sow weight and number of corpora lutea, the only effects included in the model were month of slaughter and sow genotype (or, as an alternative to sow genotype, the genetic model comprising $m, a m, d m$ and ag). In the analyses of number of attachment sites, number of embryos, embryo survival, uterine weight and uterine length, additional effects for boar genotype, the number of days between mating and slaughter and the interaction of this effect and sow genotype were fitted. For embryo survival an additional model was explored in which the number of corpora lutea was included as a linear covariate, as was the interaction between the number of corpora lutea and genotypes of sow. Analyses of uterine weight and length also explored this latter model with the addition of sow weight as a further linear covariate. The effects of number of serves and the interaction between sow weight and sow genotype were explored in initial analyses of number of attachment sites, number of embryos and embryo survival, but had no significant effect and were omitted from later analyses.

Embryonic traits. In the analyses of average distance between attachment sites, data from all attachment sites were included, whether or not they contained an apparently viable embryo. In analyses of embryo head length, embryo weight and placental weight, data were excluded from embryos that appeared degenerate and from the few embryos that were damaged during dissection. A positive relationship between the mean and variance was found for measures of embryonic and placental growth and so these data were analysed after $\log _{e}$ transformation to ameliorate this problem. Preliminary analyses were undertaken by multiple regression. The final analyses in which effects and their standard errors were estimated were undertaken by restricted maximum likelihood (REML Patterson and Thompson, 1971) and a random effect for the 
Table 2. Least squares estimates of genotype means for sow traits

\begin{tabular}{lcccc}
\hline & \multicolumn{4}{c}{ Sow genotype } \\
\cline { 2 - 5 } & $\begin{array}{c}\text { Large White } \\
\text { Trait }\end{array}$ & $\begin{array}{c}\text { Meishan } \\
\text { (LW) }\end{array}$ & $\begin{array}{c}\mathrm{F}_{1} \\
\text { (MW sire, MS dam) }\end{array}$ & (MS sire, LW dam) \\
\hline Sow weight $(\mathrm{kg})$ & $191 \pm 6.5$ & $161 \pm 7.5$ & $176 \pm 5.7$ & $176 \pm 5.8$ \\
Number of corpora lutea & $20.7 \pm 0.91$ & $27.8 \pm 1.09$ & $22.4 \pm 0.82$ & $23.3 \pm 0.82$ \\
Number of attachment sites & $15.5 \pm 0.90$ & $24.2 \pm 1.07$ & $17.9 \pm 0.80$ & $19.3 \pm 0.80$ \\
Number of viable embryos & $15.2 \pm 0.90$ & $23.4 \pm 1.08$ & $17.2 \pm 0.80$ & $18.8 \pm 0.80$ \\
Embryo survival & $0.74 \pm 0.036$ & $0.84 \pm 0.044$ & $0.78 \pm 0.033$ & $0.82 \pm 0.033$ \\
Embryo survival & $0.71 \pm 0.036$ & $0.90 \pm 0.046$ & $0.77 \pm 0.031$ & $0.82 \pm 0.031$ \\
Uterine weight $(\mathrm{kg})$ & $0.95 \pm 0.067$ & $1.08 \pm 0.076$ & $1.21 \pm 0.058$ & $1.15 \pm 0.056$ \\
Uterine weight $(\mathrm{kg})^{\mathrm{b}}$ & $0.95 \pm 0.062$ & $1.04 \pm 0.074$ & $1.23 \pm 0.051$ & $1.17 \pm 0.049$ \\
Uterine length $(\mathrm{cm})$ & $397 \pm 16$ & $357 \pm 18$ & $434 \pm 14$ & $406 \pm 13$ \\
\hline
\end{tabular}

${ }^{\mathrm{a}}$ Model including number of corpora lutea as a covariate.

${ }^{b}$ Model including number of corpora lutea and sow weight as covariates.

individual sow was included in the model. If between-sow variation had not been accounted for, standard error estimates for the effects would have been underestimated. The analyses of average distance between attachment sites, embryo head length, embryo weight and placental weight included the effects of month of slaughter, sow genotype (or, as an alternative to sow genotype, the genetic model comprising $m, a m, d m$ and $a g$ ), genotype of boar, number of days between mating and slaughter and the interaction of this latter effect with sow genotype. Additional analyses were performed for embryo head length, embryo weight and placental weight which included the withinsow effects specific to each embryo (i.e. the average distance to the adjacent embryos, the number of attachment sites in the same uterine horn, the proportional position of the embryo in the uterine horn and whether the embryo was a twin).

Within-sow variation. Genotypic effects on within-sow variation were assessed by calculating the within-sow standard deviation for each of the four $\log _{e}$ transformed traits: average distance between attachment sites, embryo head length, embryo weight and placental weight. This provided four new trait measures for each sow. These traits were then analysed by multiple regression fitting effects for month of slaughter and sow genotype (or, as an alternative to sow genotype, the genetic model comprising $m, a m, d m$ and ag), genotype of boar, number of days between mating and slaughter, sow weight and number of corpora lutea and its interaction with sow genotype. In additional analyses, the mean of each of the $\log _{e}$ transformed traits for each sow was included in the analysis of the standard deviation of the same trait.

\section{Results}

Of the 99 sows mated, 86 were found to be pregnant at slaughter. Differences in the pregnancy rate between genotypes of sows were not significant. Of the pregnant sows, 27 were slaughtered 20 days after mating, 38 were slaughtered 21 days after mating and 21 were slaughtered 22 days after mating.
Missing data from two sows meant that the analyses were performed on data from 84 sows (20 LW sows, 14 MS sows, $25 \mathrm{LW} \times \mathrm{MS}$ sows and $25 \mathrm{MS} \times \mathrm{LW}$ sows). Data from 1577 attachment sites and 1470 viable embryos were analysed. There was a total of seven apparent twin attachments, and the frequency of twin attachments did not differ significantly between genotypes when tested by a contingency chi-squared test.

\section{Sow traits}

In the analyses of sow weight, number of corpora lutea, number of attachment sites and number of embryos, only the effect of sow genotype was significant. Meishan sows were approximately $30 \mathrm{~kg}$ lighter, with 7.1 more ova, 8.7 more attachment sites and 8.2 more embryos than Large White sows $(P<0.01) . \mathrm{F}_{1}$ sows were approximately intermediate between the two pure breeds (Table 2). The genetic model analyses (Table 3) showed that for these traits the sow genotype differences were due to the additive effect of maternal genes (i.e. those of the sow), thus the reciprocal $F_{1}$ sows did not differ significantly from one another or, on average, from the mean of the two pure breeds.

Embryo survival differed significantly $(P<0.05)$ between sow genotypes owing to an additive effect of maternal genes, and $F_{I}$ sows were approximately intermediate between the pure breeds. The partial regression of embryo survival on the number of corpora lutea was significant $(-0.0131 \pm 0.0042)$. The inclusion of this effect in the model (and thus the adjustment of embryo survival to a common mean value of the number of corpora lutea) increased the advantage of the Meishan over the Large White in the proportion surviving from approximately 0.10 to approximately 0.20 (Table 2 ). The effect of number of days between mating and slaughter approached significance $(P=0.1-0.05)$, with embryo survival declining as the day of gestation increased (Table 4).

Uterine weight differed significantly $(P<0.05)$ between sow genotypes. Although Meishan sows had slightly heavier uteri than Large White sows, this effect (i.e. am) was not significant 
Table 3. Least squares estimates of genetic effects for sow traits

\begin{tabular}{lcccc}
\hline & & & Genetic effect & \\
\cline { 2 - 5 } & $\begin{array}{c}\text { m; mid-parental } \\
\text { value }\end{array}$ & $\begin{array}{c}\text { am; maternal } \\
\text { additive effect }\end{array}$ & $\begin{array}{c}d m \text {; maternal } \\
\text { heterosis effect }\end{array}$ & $\begin{array}{c}\text { ag; grandmaternal } \\
\text { additive effect }\end{array}$ \\
\hline Sow weight $(\mathrm{kg})$ & $176 \pm 5.0$ & $-15.3 \pm 6.4$ & $0.5 \pm 6.4$ & $0.2 \pm 4.1$ \\
Number of corpora lutea & $24.2 \pm 0.71$ & $3.98 \pm 0.92$ & $-1.40 \pm 0.92$ & $-0.44 \pm 0.58$ \\
Number of attachment sites & $19.9 \pm 0.70$ & $5.14 \pm 0.90$ & $-1.36 \pm 0.90$ & $-0.78 \pm 0.57$ \\
Number of viable embryos & $19.3 \pm 0.70$ & $4.95 \pm 0.90$ & $-1.31 \pm 0.90$ & $-0.80 \pm 0.57$ \\
Embryo survival & $0.82 \pm 0.040$ & $0.072 \pm 0.037$ & $0.008 \pm 0.037$ & $-0.019 \pm 0.023$ \\
Embryo survival & $0.84 \pm 0.038$ & $0.124 \pm 0.039$ & $-0.010 \pm 0.036$ & $-0.026 \pm 0.022$ \\
Uterine weight $(\mathrm{kg})$ & $0.82 \pm 0.075$ & $0.033 \pm 0.062$ & $0.166 \pm 0.071$ & $0.030 \pm 0.039$ \\
Uterine weight $(\mathrm{kg})$ & $0.80 \pm 0.066$ & $0.013 \pm 0.063$ & $0.204 \pm 0.063$ & $0.032 \pm 0.034$ \\
Uterine length $(\mathrm{cm})$ & $396 \pm 18$ & $-34 \pm 15$ & $43 \pm 17$ & $14 \pm 9$ \\
\hline
\end{tabular}

${ }^{a}$ Model including number of corpora lutea as a covariate.

'Model including number of corpora lutea and sow weight as covariates.

Table 4. Least squares (or restricted maximum likelihood for embryo traits) estimates of number of days between mating and slaughter of sows

\begin{tabular}{lrrr}
\hline & \multicolumn{4}{c}{ Number of days between mating and slaughter } \\
\cline { 2 - 4 } Trait & 20 & 21 & 22 \\
\hline Embryo survival & $0.82 \pm 0.032$ & $0.81 \pm 0.027$ & $0.73 \pm 0.036$ \\
Uterine weight $(\mathrm{kg})$ & $0.97 \pm 0.056$ & $1.12 \pm 0.044$ & $1.26 \pm 0.062$ \\
Embryonic head length & $5.27 \pm 0.029$ & $5.44 \pm 0.023$ & $5.67 \pm 0.033$ \\
$\quad \log _{\mathrm{e}}$ graticule units) & & & \\
Embryonic weight $\left(\log _{\mathrm{e}} \mathrm{g}\right)$ & $3.27 \pm 0.076$ & $-2.83 \pm 0.062$ & $-2.17 \pm 0.088$ \\
Placental weight $\left(\log _{\mathrm{e}} \mathrm{g}\right)(\mathrm{PW})$ & $0.70 \pm 0.094$ & $1.06 \pm 0.077$ & $1.66 \pm 0.110$ \\
Within-sow standard & $0.37 \pm 0.022$ & $0.44 \pm 0.017$ & $0.56 \pm 0.024$ \\
$\quad$ deviation of PW & & & \\
\hline
\end{tabular}

and the genotype differences were due to maternal heterosis, with $\mathrm{F}_{1}$ sows having significantly heavier $(P<0.05)$ uteri than sows of either pure breed. The partial regressions of uterine weight on sow weight and on the number of corpora lutea were significant $(0.0037 \pm 0.0010$ and $0.0184 \pm 0.0066$, respectively) $(P<0.01)$, but adjusting to common mean values of these traits did not alter the results markedly (Tables 2 and 3). Uterine weight increased significantly with the number of days between mating and slaughter (Table 4).

Total uterine length differed significantly $(P<0.01)$ between sow genotypes: the uteri of Meishan sows were shortest and those of $F_{1}$ sows were longest (Table 2). Both maternal additive genetic effects $(\mathrm{am})$ and maternal heterosis $(\mathrm{dm})$ were significant causes of sow genotypic differences (Table 3 ).

\section{Embryonic traits}

Sow genotype was a significant $(P<0.05)$ effect on the logarithm of the distance between attachment sites. The distance between attachment sites was least in the Meishan and greatest in the Large White, but the distance in the $F_{1}$ sows was not much less than in the Large White (Table 5). Both the maternal additive $(\mathrm{am})$ and maternal heterosis $(\mathrm{dm})$ effects were significant (Table 6) as was the grandmaternal additive effect (ag).

The sow genotype did not have a significant effect on the logarithm of head length and embryos in the two purebred sows were very similar (Table 5). Embryos in the $F_{1}$ sows were larger than those in purebred sows, however, and the effect of maternal heterosis was significant $(P<0.05)$. The partial regression of the logarithm of head length on the average distance to adjacent embryos was significant $(0.0219 \pm 0.0091$; $P<0.05$ ), but adjusting for this trait did not affect the genotypic differences between sows. The trait increased significantly $(P<0.05)$ with the number of days between mating and slaughter (Table 4).

Embryonic weight was least in the Meishan sows and greatest in $F_{I}$ sows (Table 5) but neither sow genotype nor any of the genetic effects were significant influences on the logarithm of this trait. Embryonic weight increased with the average distance to adjacent embryos and the partial regression was significant $(0.0838 \pm 0.0264 ; P<0.01)$. Embryonic weight also increased significantly with the number of days between mating and slaughter (Table 4).

The effect of sow genotype on the logarithm of placental weight was significant. Although placental weight in Meishan 
Table 5. Restricted maximum likelihood estimates of genotype means for traits of pig embryos

\begin{tabular}{|c|c|c|c|c|}
\hline \multirow[b]{2}{*}{ Trait } & \multicolumn{4}{|c|}{ Sow genotype } \\
\hline & $\begin{array}{l}\text { Large White } \\
\text { (LW) }\end{array}$ & $\begin{array}{l}\text { Meishan } \\
\text { (MS) }\end{array}$ & $\begin{array}{c}\mathrm{F}_{1} \\
(\mathrm{LW} \text { sire, } \mathrm{MS} \text { dam) }\end{array}$ & $\begin{array}{c}\mathrm{F}_{1} \\
\text { (MS sire, LW dam) }\end{array}$ \\
\hline $\begin{array}{l}\text { Mean distance to adjacent attachment sites } \\
\left(\log _{\mathrm{e}} \mathrm{mm}\right)(\mathrm{DS})\end{array}$ & $5.78 \pm 0.056$ & $5.29 \pm 0.067$ & $5.76 \pm 0.048$ & $5.62 \pm 0.049$ \\
\hline Embryonic head length ( $\log _{e}$ graticule units) $(E H)$ & $5.42 \pm 0.033$ & $5.42 \pm 0.040$ & $5.50 \pm 0.029$ & $5.50 \pm 0.029$ \\
\hline Embryonic head length ( $\log _{e}$ graticule units) & $5.40 \pm 0.036$ & $5.42 \pm 0.043$ & $5.48 \pm 0.033$ & $5.48 \pm 0.033$ \\
\hline Embryonic weight $\left(\log _{e} g\right)(E W)$ & $-2.74 \pm 0.086$ & $-2.92 \pm 0.105$ & $-2.70 \pm 0.079$ & $-2.68 \pm 0.076$ \\
\hline Embryonic weight $\left(\log _{e} g\right)^{\mathrm{a}}$ & $-2.79 \pm 0.097$ & $-2.90 \pm 0.116$ & $-2.74 \pm 0.090$ & $-2.71 \pm 0.088$ \\
\hline Placental weight $\left(\log _{\mathrm{e}} \mathrm{g}\right)(\mathrm{PW})$ & $1.19 \pm 0.107$ & $0.83 \pm 0.130$ & $1.27 \pm 0.098$ & $1.28 \pm 0.094$ \\
\hline Placental weight $\left(\log _{e} g\right)^{a}$ & $1.40 \pm 0.133$ & $1.22 \pm 0.154$ & $1.50 \pm 0.125$ & $1.56 \pm 0.123$ \\
\hline Within-sow standard deviation of DS & $0.42 \pm 0.030$ & $0.35 \pm 0.035$ & $0.33 \pm 0.027$ & $0.30 \pm 0.025$ \\
\hline Within-sow standard deviation of $\mathrm{DS}^{\mathrm{b}}$ & $0.44 \pm 0.030$ & $0.30 \pm 0.039$ & $0.35 \pm 0.026$ & $0.30 \pm 0.025$ \\
\hline Within-sow standard deviation of EH & $0.10 \pm 0.017$ & $0.08 \pm 0.020$ & $0.10 \pm 0.015$ & $0.08 \pm 0.015$ \\
\hline Within-sow standard deviation of EW & $0.28 \pm 0.025$ & $0.25 \pm 0.029$ & $0.19 \pm 0.022$ & $0.20 \pm 0.021$ \\
\hline Within-sow standard deviation of EW & $0.28 \pm 0.024$ & $0.26 \pm 0.027$ & $0.19 \pm 0.021$ & $0.19 \pm 0.020$ \\
\hline Within-sow standard deviation of PW & $0.47 \pm 0.026$ & $0.42 \pm 0.029$ & $0.44 \pm 0.023$ & $0.45 \pm 0.022$ \\
\hline Within-sow standard deviation of $\mathrm{PW}^{\mathrm{b}}$ & $0.47 \pm 0.024$ & $0.46 \pm 0.029$ & $0.43 \pm 0.021$ & $0.44 \pm 0.020$ \\
\hline
\end{tabular}

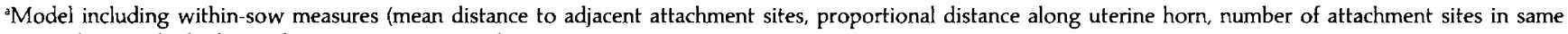
uterine horn and whether embryo a twin or not) as linear covariates.

'Model including sow mean for the trait as a linear covariate.

Table 6. Restricted maximum likelihood estimates of genetic effects for traits of pig embryos

Genetic effect

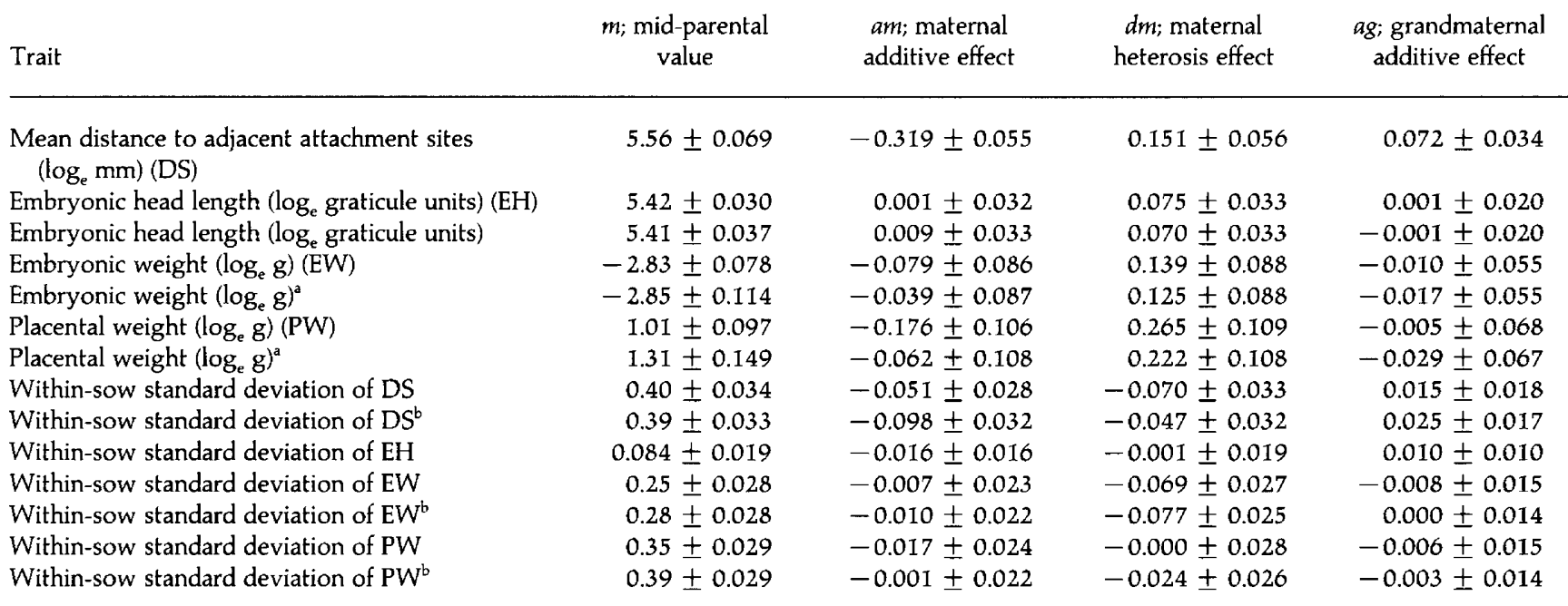

${ }^{2}$ Model including within sow measures (mean distance to adjacent attachment sites, proportional distance along uterine horn, number of attachment sites in same uterine horn and whether embryo a twin or not) as linear covariates.

bodel including sow mean for the trait as a linear covariate.

sows was lower than in Large White sows, this difference was not significant and the major reason for the significant effect of sow genotype was the high placental weight in $\mathrm{F}_{1}$ sows (Table $5)$, which resulted in a significant $(P<0.05)$ maternal heterosis effect (Table 6). The partial regression of the logarithm of placental weight on the average distance to adjacent embryos was significant $(0.192 \pm 0.047)$, although adjusting for this trait did not greatly affect the sow genotypic differences. Placental weight increased significantly $(P<0.01)$ with the number of days between mating and slaughter (Table 4).

The effect of sow genotype on the within female standard deviation of the logarithm of the distance between attachment sites was significant $(P<0.05)$, and Large White sows had the highest mean (Table 5). The partial regression of the standard 
deviation on the mean was significant $(-0.142 \pm 0.053$; $P<0.05$ ) and with the inclusion of this effect in the model a previously significant effect of maternal heterosis became nonsignificant and the maternal additive effect became significant $(P<0.01)$. Thus after adjustment for this effect, the standard deviation of the logarithm of the distance between attachment sites was least in the Meishan and greatest in the Large White, with the $F_{1}$ sows having values close to that of the purebred Meishan (Table 5).

None of the effects in the analysis of the within-sow standard deviation of the logarithm of head length was significant and differences between the sow genotypes were relatively small.

The within-sow standard deviation of the logarithm of embryonic weight was markedly less in $F_{1}$ sows than in either pure breed and thus the estimate of maternal heterosis was significant $(P<0.05)$ and negative. The partial regression of the within-sow standard deviation on the sow mean was significant $(0.077 \pm 0.021 ; P<0.01)$, but adjustment for this effect did not greatly change estimates of differences between sow genotypes.

There were no differences between sow genotypes for the within sow standard deviation of the logarithm of placental weight either before or after adjustment for a significant partial regression on the sow mean logarithm of placental weight (estimated at $0.110 \pm 0.029$ ). The within-sow standard deviation increased with the number of days between mating and slaughter (Table 4).

\section{Discussion}

The results of this study confirm that one component of prolificacy in Meishan females is an advantage in the survival of embryos. They also indicate, however, that $F_{1}$ crossbred females must achieve their prolificacy via a slightly different route and point to some factors that might be involved in this difference.

This study supports the findings of previous studies (Ashworth et al., 1990; Haley and Lee, 1990; Ashworth et al., 1992; Wilmut et al., 1992) of gilts and sows from the sample of Meishan breed in the UK in showing that they have a significantly greater ovulation rate (number of corpora lutea) than do control Large White females of a similar age. The breed difference appears to increase with parity, being about four in the first parity (Haley and Lee, 1990; Wilmut et al., 1992), five ova in the second parity (Haley and Lee, 1990) and, in the third parity, seven ova in this study and eight in the study of Wilmut et al. (1992). In common with the genetic study of Haley and Lee (1990), this breed difference is under additive genetic control, and $F_{1}$ sows have ovulation rates that do not differ significantly from the mean of the pure breeds.

The difference between the Meishan and Large White sows in the number of embryos attaching and surviving to days $20-22$ is greater than that for ovulation rate owing to higher proportionate survival in Meishan sows. In fact, after adjustment for the partial regression of embryo survival on ovulation rate, the breed difference in the proportion of embryos surviving is predicted to be about 0.2 . In the study of Bazer et al. (1988), survival at day 30 of gestation was 0.55 in Large White gilts with 18.5 corpora lutea and 0.89 in Meishan gilts with 14.1 corpora lutea. In the control (i.e. not Regumate-treated) gilts studied by Ashworth et al. (1992), survival at day 27-31 of gestation was 0.72 in crossbred Landrace $\times$ Large White gilts with 14.7 corpora lutea and 0.80 in Meishan gilts with 19.4 corpora lutea. The regression of survival on ovulation rate is about -0.01 in early gestation (Wrathall, 1971; Ashworth ef al., 1992; present study) and after adjustment to a common ovulation rate, the difference in favour of the Meishan would therefore be about 0.3 in the study of Bazer et al. (1988) and 0.15 in the study of Ashworth et al. (1992). Given the inherent between-sow variability in embryo survival and the relatively small sample sizes, these two studies are not inconsistent with the one reported here. Taken together these three studies suggest that, at a common ovulation rate, the advantage of Meishan over European white breed females in embryo survival in early gestation would be about 0.2 .

The breed difference in embryo survival in early gestation is similar to that found for the breed difference in prenatal survival at term after adjustment for ovulation rate (Haley and Lee, 1990). However, it is likely that factors acting after day 20 are also important for the prolificacy of the Meishan, as embryo transfer and multiple ovulation studies suggest that European breeds carrying larger than normal numbers of viable embryos in early gestation would lose them prior to parturition (e.g. see Wrathall, 1971). It is therefore likely that Meishan females have a greater 'uterine capacity' and thus can maintain a higher number of fetuses than can other breeds.

The relationship between uterine capacity and uterine size is uncertain, and in fact this study confirms that of Bazer et al. (1988) in showing that the Meishan pig has a shorter uterus than the Large White. Unlike the study of Bazer et al. (1988), which was of young gilts, in this study the weight of sows did not significantly affect uterine length and did not account for the breed difference. Comparative uterine dimensions in early gestation may, however, differ from those in later gestation when they perhaps have a greater effect on fetal survival.

At term, individual Meishan piglets are about 20-25\% lighter than those from Large White females and this difference is controlled by maternal rather than fetal genes (Bidanel et al., 1990b; Haley and Lee, 1990). The breed difference in fetal weight can be observed as early as day 30 of gestation, with embryo transfer studies showing that maternal genes are also largely responsible for the difference at this stage (Ashworth et al., 1990, 1992). In the studies reported here, fetuses collected 20-22 days after mating from Meishan females tend to weigh less than those from Large White females, but this difference does not approach significance. The difference in piglet weights and fetal weights at day 30 of gestation may not be a simple consequence of crowding, as adjustment for litter size does not greatly alter the breed differences either in fetal weight (Ashworth et al., 1990, 1992) or in piglet weight (Bidanel et al., 1990b; Haley et al., 1992). Thus the ability of the Meishan female to produce smaller fetuses and piglets which remain viable may be important and the maternal control of fetal growth may be central to the maintenance of a high litter size.

A further factor that may influence uterine capacity is the control of spacing between fetuses. Variation in the distance between embryos is less in Meishan sows than in Large White sows. This could be achieved either by more even attachment or by differential growth of the uterus after attachment. The latter explanation seems unlikely at this early stage of gestation. Whatever the cause, the results may be that the extremes 
of competition between closely sited fetuses are avoided, leading to a reduction in fetal mortality compared with that in Large White sows.

Previous studies of litter size at term have shown that $F_{1}$ gilts and sows produce litters as large or larger than purebred Meishan females. Genotypic differences are mainly controlled by the maternal genotype, and so there is a marked maternal heterosis for litter size (Bidanel et al., 1989; Haley and Lee, 1990). In the study of Haley and Lee (1990), the $F_{1}$ gilts were intermediate in ovulation rate. Thus the prolificacy of the $F_{1}$ females was due mainly to heterosis leading to prenatal survival which was proportionately 0.1 higher than in either purebred (although after adjustment for an association with ovulation rate, prenatal survival was similar in $\mathrm{F}_{1}$ and purebred Meishan sows; Haley and Lee, 1990). In this study, the reproductive performance of $F_{1}$ sows in early gestation, in terms of the number of corpora lutea, the number of attachment sites, the number of embryos and the proportionate embryo survival (whether or not adjusted for the number of corpora lutea), was intermediate between the two pure breeds. Thus there is no evidence for maternal heterosis for early reproductive performance in $F_{1}$ sows. These results imply that $F_{1}$ sows have a very high level of fetal survival in comparison with the purebred females allowing them to reach similar litter sizes to those of Meishan sows.

The results of this study point to several, possibly interrelated, factors that may contribute to heterosis for fetal survival. First, there was heterosis for uterine measures: uteri from $F_{1}$ females are both longer and heavier than those from either pure breed. A consequence of this is that spacing between embryos in $\mathrm{F}_{1}$ sows approached that in Large White sows carrying fewer embryos. Second, there was positive maternal heterosis for all measures of fetal and placental growth (although that for embryonic weight was not significant). Embryos from $F_{1}$ sows were heavier, had longer heads and heavier placentae than those from either breed of purebred sow. Third, there was some evidence for maternal heterosis for reduced within-sow variation. Measures of maternal heterosis for variation in distances between embryos, embryonic head length, embryonic weight and placental weight were all negative, although only significantly so for variation in embryonic weight and for variation in the distance between embryos before adjustment for the mean distance between embryos.

In summary, at days 20-22 of gestation, Meishan third parity sows were found to have more corpora lutea, attachment sites and embryos and a higher level of proportionate embryo survival than did Large White sows of a similar age and parity. $F_{1}$ sows were intermediate in performance for these traits, suggesting that there must be high levels of heterosis for fetal survival for this genotype to achieve a similar litter size to purebred Meishan sows at term. Factors contributing to the heterosis in fetal survival may be the maternal heterosis for increased uterine size and embryonic and placental growth and for reduced variability observed in this study. Future studies should compare fetal survival and uterine capacity in Meishan, Large White and crossbred sows and attempt to identify the factors controlling between genotype differences in embryonic growth and variability and their involvement in differences in fetal survival.
We are very grateful to the staff of Mountmarle farm and the Large Animal Unit for their exemplary care of the animals. This study was partly funded by the Agricultural and Food Research Council and by the Ministry of Agriculture, Fisheries and Food.

\section{References}

Anderson LH, Christenson LK, Christenson RK and Ford SP (1991) Embryonic diversity and estrogen content of littermate embryos from Chinese (Meishan) and crossbred sows Journal of Animal Science 69 (Supplement 1) 410

Ashworth CJ, Haley CS, Aitken RP and Wilmut I (1990) Embryo survival and fetal growth following reciprocal embryo transfer between Chinese Meishan and Large White gilts Journal of Reproduction and Fertility 90 595-603

Ashworth CJ, Haley CS and Wilmut I (1992) Effect of regumate on ovulation rate, embryo survival and conceptus growth in Meishan and Landrace $\times$ Large White gilts Theriogenology 37 433-443

Bazer FW, Thatcher WW, Martinat-Botte F and Terqui M (1988) Conceptus development in Large White and prolific Chinese Meishan pigs Joumal of Reproduction and Fertility 84 37-42

Bidanel JP, Caritez JC and Legault C (1989) Estimation of crossbreeding parameters between Large White and Meishan porcine breeds. I. Reproductive performance Genetics, Selection, Evolution 21 507-526

Bidanel JP, Caritez JC and Lagant H (1990a) Ovulation rate and embryonic survival in gilts and sows with variable proportions of Meishan (MS) and Large White (LW) genes. Mean performance and crossbreeding parameters between MS and LW breeds. In Symposium sur le Porc Chinois pp 109-110 Eds M Molenat and C Legault. INRA, Paris

Bidanel JP, Caritez JC and Legault C (1990b) Estimation of crossbreeding parameters between Large White and Meishan porcine breeds. II. Growth before weaning and growth of females during the growing and reproductive periods Genetics, Selection, Evolution 22 431-455

Bolet G, Martinat Botte F, Locatelli A, Gruand J, Terqui M and Berthelot F (1986) Components of prolificacy in hyperprolific Large White sows compared with the Meishan and Large White breeds Genetics, Selection, Evolution 18 333-342

Cameron ND, Curran MK and Thompson R (1988) Estimation of sire with feeding regime interaction in pigs Animal Production 46 87-95

Cheng, P-L (1983) A highly prolific pig breed of China - The Taihu pig Pig News and Information 4 407-425

Dickerson GE (1969) Experimental approaches in utilising breed resources Animal Breeding Abstracts 37 191-202

Draper NR and Smith H (1966) Applied Regression Analysis pp 171-172. John Wiley and Sons, New York

GENSTAT 5 Committee (1989) Genstat 5 Reference Manual. Clarendon Press, Oxford

Haley CS and Lee GJ (1990) Genetic components of litter size in Meishan and Large White pigs and their crosses. In Proceedings of the 4th World Congress on Genetics Applied to Livestock Production XV pp 458-481 Eds WG Hill, R Thompson and JA Woolliams. Organising Committee, Edinburgh

Haley CS, D'Agaro E and Ellis M (1992) Genetic components of growth and ultrasonic fat depth traits in Meishan and Large White pigs and their reciprocal crosses Animal Production 54 105-115

Patterson HD and Thompson R (1971) The recovery of inter-block information when block sizes are unequal Biometrika 58 545-554

Perry JS (1981) The mammalian fetal membranes Joumal of Reproduction and Fertility 62 32.1-335

Serra JJ, Ellis M and Haley CS (1992) Genetic components of carcass and meat quality traits in Meishan and Large White pigs and their reciprocal crosses Animal Production 54 117-127

Wilmut I, Haley CS, Ashworth CJ, Aitken RP and Ritchie W (1990) Embryo development and embryo transfer in Meishan and Large White pigs. In Proceedings of the 4th World Congress on Genetics Applied to Livestock Production XVI pp 347-350 Eds WG Hill, R Thompson and JA Woolliams. Organising Committee, Edinburgh

Wilmut I, Ritchie W, Haley CS, Ashworth CJ and Aitken RP (1992) A comparison of rate and uniformity of embryo development in Meishan and Large White pigs Journal of Reproduction and Fertility 95 45-56

Wrathall AE (1971) Prenatal Survival in Pigs. Part 1. Ovulation Rate and its Influence on Prenatal Survival and Litter Size in Pigs. Commonwealth Agricultural Bureaux, Farnham Royal 